\title{
Studies on tableting properties of lactose. VII. The effect of variations in primary particle size and percentage of amorphous lactose in spray dried lactose products
}

\author{
H. Vromans ${ }^{1}$, G.K. Bolhuis ${ }^{1}$, C.F. Lerk, H. van de Biggelaar ${ }^{2}$ and H. Bosch ${ }^{3}$ \\ ${ }^{I}$ Laboratory for Pharmaceutical Technologv and Dispensing. Groningen (The Netherlands); ${ }^{2}$ DMV. Veghel (The Netherlands); \\ and ${ }^{3}$ Department of Chemical Technology, Twente University of Technology, Enschede (The Netherlands)
}

(Received 7 May 1986)

(Modified version received 23 June 1986)

(Accepted 17 August 1986)

Key words: Lactose; Amorphous; Binder; Tableting property; Spray drying; Compactibility; Particle size; Consolidation

\begin{abstract}
Summary
Sieve fractions of $\alpha$-lactose monohydrate and dicalcium phosphate dihydrate, respectively, suspended in solutions of lactose, were spray dried in order to obtain products with various amorphous lactose contents. The compactibility of the samples appeared to be a function of both the primary particle size and the amount of amorphous lactose. The lactose glass was considered to form a binding layer on the particle surface area. Its efficacy was found to be determined by the size and the consolidation of the particles at lower percentages, whereas the specific properties of fully amorphous spray dried lactose, e.g. its susceptibility to water uptake and magnesium stearate mixing, were brought out especially at high percentages.
\end{abstract}

\section{Introduction}

Lactose is a widely used excipient in pharmaceutical tableting. It exists in an $\alpha$ - and a $\beta$-form, can be either crystalline or amorphous, while $\alpha$ lactose monohydrate can be dehydrated to stable or unstable anhydrous $\alpha$-lactose. These various lactose products all exhibit different compaction properties (e.g. Bolhuis et al., 1985; Fell and Newton, 1971). The aim of the studies on tableting properties of lactose is to determine the factors which are responsible for the occurrence of the

Correspondence: H. Vromans, Laboratory for Pharmaceutical Technology and Dispensing, Antonius Deusinglaan 2, 9713 AW Groningen, The Netherlands. different tableting characteristics of the compound.

The work was commenced with a study of the compactibility properties of different types of crystalline lactose. $\alpha$-Lactose monohydrate is generally considered to exhibit brittle fracture on compaction. It is obvious, however, that fragmentation is not complete; this can be argued from the observation that a decrease in particle size of the starting material resulted in an increase in both tablet thickness and tablet strength (Vromans et al., 1985a).

Mercury porosimetry measurements have been used to calculate tablet pore surface areas (Vromans et al., 1985b). It appeared that the tablet pore surface area increased with increasing com- 
paction load for all the types of crystalline lactose investigated. Assuming a proportionality between the change in pore surface area and the alteration in the actual binding surface area, it was found that one unique relationship exists between crushing strength and pore surface area for all different types of crystalline lactose and also for different sieve fractions of $\alpha$-lactose monohydrate (De Boer et al., 1986). From this it was concluded that fragmentation is the predominant mechanism of consolidation for the types of crystalline lactose. Moreover, this means that the actual size of the surface area is more important for the tablet strength than the initial particle size. This confirmed the outcomes of the first study in this series (Vromans et al., 1985a), where it was stated that the contribution of mechanical activation processes on compactibility is probably overestimated in some respects. It has been demonstrated that the degree of fragmentation diminished with decreasing initial particle size (Alderborn and Nyström, 1985; De Boer et al., 1986). Therefore the role of plastic and elastic deformation probably will increase instead.

Amorphous lactose, prepared by spray drying was found to have totally different compaction properties (Vromans et al., 1986). The compactibility of the material was found to increase considerably after absorption of water vapor. From the results obtained with mercury porosimetry it was concluded that consolidation of the amorphous lactose could be considered to occur mainly by plastic flow. This became more likely after the observation that the material exhibited a large susceptibility to magnesium stearate mixing, whereas the effect of water uptake on the consolidation and compaction could also be explained with this.

Commercially available spray dried lactose (DCLactose 11) contains about $15 \%$ amorphous lactose and $85 \%$ crystalline $\alpha$-lactose monohydrate (Kussendrager et al., 1981). Consolidation of this product was shown to be mainly determined by the crystalline component. The binding properties were considerably affected by the amorphous lactose, however. This exposes the complex nature of this spray dried excipient. In the previous study (Vromans et al., 1986) it was suggested that the amorphous part of the product forms a binding layer on the $\alpha$-lactose monohydrate crystals. The exact mechanism of the increased binding properties of the product has not been fully elucidated until now, however.

In the present paper, the effects of alterations in primary particle size and variations in the amount of amorphous material within the products are discussed.

\section{Materials and Methods}

The samples used in this study were prepared by spray drying and were composed of crystalline particles (primary particles) "glued" together to aggregates (secondary particles) by amorphous lactose (glass). The primary particles consisted of either $\alpha$-lactose monohydrate or dicalcium phosphate dihydrate (DCP) (Emcompress, Edward Mendell, New York, U.S.A.). These materials were milled and fractionated using air classifiers (Alpine Multi-Plex Labor Zickzacksichter 100MZR, and Alpine Turboplex Feinsichter, type 50ATP, Alpine AG, F.R.G.). Fractionation of the products was checked by coulter counter analysis (Coulter Counter model TA2, Coulter Electronics, Luton, U.K.). The sieve fractions were used as the starting material for spray drying, which occurred with a A/S Niro Atomizer (Niro, Copenhagen, Denmark) for the lactose products and with an Anhydro spray dryer type Lab S1 (Anhydro, Copenhagen, Denmark) for the DCP-products. The amount of lactose, dissolved at the moment of evaporation, determines the quantity of amorphous lactose present in the final product. Therefore the lactose sieve fractions were suspended in saturated aqueous lactose solutions at temperatures of $5.5 \pm$ $1,32.5 \pm 1,50 \pm 1$ and $65 \pm 1^{\circ} \mathrm{C}$, respectively, in order to obtain amorphous lactose percentages of about $15,30,50$ and $75 \%$, respectively.

The samples were stored at various atmospheric conditions in a humidity test chamber (Hereaus Tropic Klimaprüfschranke VTRK 150, Hereaus Vötsch GmbH, F.R.G.). The total water content of the products was determined with a semi-micro method, using Merck's Karl Fischer Reagents (E. Merck, Darmstadt, F.R.G.). Assuming the $\alpha$ - 
lactose monohydrate to have a constant amount of water of crystallization ( $5 \%$ ), the residual amount of water was considered to be absorbed by the amorphous part of the products.

Electron micrographs were made using a scanning electron microscope (Jeol JSM-U3, Jeol, Tokyo, Japan). Prior to investigation, the samples were coated with gold, using a direct current sputter technique. The specific surface area $\left(S_{v}\right)$ of the materials was measured with a self-constructed permeability apparatus. The arithmetical mean particle diameter of the sieve fractions was used to calculate the powder surface area $\left(\mathrm{S}_{\mathrm{c}}, \mathrm{m}^{2} / \mathrm{g}\right)$ on the basis of spherical particles.

Compaction of tablets was carried out using a hydraulic press (Hydro Mooi/Automation Peekel, The Netherlands). A weighed quantity of $500 \mathrm{mg}$ was compressed at a constant relative humidity of $55 \%$ in a prelubricated die with flat-faced punches, having a diameter of $13 \mathrm{~mm}$, at a compression speed of $2 \mathrm{kN} / \mathrm{s}$. The crushing strength of the tablets was measured $15 \mathrm{~min}$ after compaction with a Schleuniger 2E instrument (Dr. Schleuniger Productronic AG, Solothurn, Switzerland).

Tablet dimensions were determined using an electronic micrometer (Mitutoyo MFE Co., Tokyo, Japan) with an accuracy of $0.001 \mathrm{~mm}$. Within $48 \mathrm{~h}$ after compaction the samples were subjected to mercury porosimetry measurements, which were carried out with the aid of a Carlo Erba Porosimeter series 200 (Carlo Erba Strumentazione SpA, Milano, Italy). The tablets were evacuated at about $10 \mathrm{~Pa}$ prior to the measurements for at least half an hour.

\section{Results and Discussion}

With the spray drying technique spherical particles can be obtained, which shape is supposed to be an important contribution to the good flow properties of the product (Bolhuis et al., 1985). A prerequisite for acquiring spherical aggregates is that the primary particles easily fit in the spray droplets. In our relatively small research spray dryer it was possible to produce aggregates with a size in the magnitude of $30-40 \mu \mathrm{m}$. The dimensions of the primary particles varied from 1 to 45 $\mu \mathrm{m}$. It appeared that not all products were ideal spherically shaped, while also the mutual sizes of the spray dried products varied little (Table 1). In order to study the importance of these variations a preliminary pilot survey was done in which two spray dried samples with totally different morphologies were compared.

With the aid of the research spray dryer a testing batch was produced, using the starting material which is normally used for the production of the commercially available spray dried lactose (DCLactose 11). It can be seen from Fig. 1 that the product obtained possesses a totally different morphology compared with the normal commercial excipient. Next to the characteristic spherical aggregates, also separate crystals are present. This can easily be understood by pointing to the difference in the size of the equipment used. For the manufacturing of DCLactose 11 large spray dryers are used in which the spray droplets are large enough to take up also the largest crystalline particles.

Regarding the tableting properties of the two products (Table 2), the compactibility appears to be about the same. Obviously it is not very important whether the crystals are fully incorporated within the aggregates or not. Also it might be concluded that the structure of the aggregates is destroyed very easily on compaction, after which the differences between the two products are annihilated.

Figs. 2 and 3 show the crushing strength of different spray dried products at different moisture levels. In Table 1 some additional properties are depicted. In Fig. 2 the values of the starting materials as such are also given in order to show the considerable increase in tablet strength after spray drying. Considering the Figs. 2 and 3 and Table 1 it can be noticed that the crushing strength of products with a low amorphous lactose content seems to be mainly determined by the size of the primary particles. The compactibility of these samples is hardly dependent on the moisture content. However, with larger amounts of amorphous lactose the specific characteristics of fully amorphous spray dried lactose (Vromans et al., 1986) become more and more pronounced; compact strengths are highly dependent on the quantity of 
TABLE 1

Some (tableting) properties of spray dried lactose samples

\begin{tabular}{|c|c|c|c|c|}
\hline \multicolumn{3}{|c|}{ Data of the spray dried samples } & \multicolumn{2}{|c|}{ Data of the compacts } \\
\hline $\begin{array}{l}\text { Prim. part. } \\
\text { size }(\mu \mathrm{m})\end{array}$ & $\begin{array}{l}\text { Perc. amorphous } \\
\text { lactose }(\%)\end{array}$ & $\begin{array}{l}\text { Spec. surface } \\
\text { area } \\
\left(\times 10^{5} \mathrm{~m}^{-1}\right)\end{array}$ & $\begin{array}{l}\text { Crushing strength } \\
\text { unlubricated } \\
(2 \% \text { water })(\mathrm{kg})\end{array}$ & $\begin{array}{l}\text { Crushing strength } \\
\text { lubricated } \\
(2 \% \text { water) }(\mathrm{kg})\end{array}$ \\
\hline $1-8$ & 15 & 3.3 & $15.6 \pm 1.2$ & $11.7 \pm 0.4$ \\
\hline $1-8$ & 30 & 2.7 & $18.2 \pm 1.5$ & $11.4 \pm 0.5$ \\
\hline $1-8$ & 50 & 2.3 & $16.0 \pm 0.7$ & $7.2 \pm 0.3$ \\
\hline $8-16$ & 15 & 2.5 & $10.9 \pm 0.7$ & $6.4 \pm 0.1$ \\
\hline $8-16$ & 30 & 2.1 & $11.6 \pm 0.4$ & $4.2 \pm 0.1$ \\
\hline $8-16$ & 50 & 1.7 & $10.0 \pm 0.4$ & $1.7 \pm 0.2$ \\
\hline $8-16$ & 75 & 1.5 & $6.0 \pm 0.7$ & 0 \\
\hline $16-24$ & 15 & 2.1 & $8.5 \pm 0.3$ & $4.3 \pm 0.3$ \\
\hline $16-24$ & 30 & 1.9 & $9.2 \pm 0.2$ & $3.5 \pm 0.3$ \\
\hline $24-32$ & 30 & 1.9 & $7.8 \pm 0.4$ & $<1$ \\
\hline $24-32$ & 50 & 1.9 & $7.2 \pm 0.4$ & 0 \\
\hline $24-32$ & 75 & 1.8 & $5.4 \pm 0.2$ & 0 \\
\hline $32-45$ & 15 & 1.9 & $6.5 \pm 0.2$ & $<1$ \\
\hline $32-45$ & 30 & 1.9 & $6.5 \pm 0.3$ & $<1$ \\
\hline $32-45$ & 50 & 1.8 & $6.5 \pm 0.3$ & 0 \\
\hline $32-45$ & 75 & 1.9 & $5.2 \pm 0.6$ & 0 \\
\hline
\end{tabular}

The specific surface areas were determined with the permeametry method. Lubrication occurred by mixing the samples with $1.0 \%$ magnesium stearate during $30 \mathrm{~min}$ in a Turbula mixer at $90 \mathrm{rpm}$. Tablets were compacted at a pressure of $75 \mathrm{MPa}$. The percentage water indicated represents the amount of moisture on the amorphous part of the spray dried lactose. (Crushing strength \pm S.D.)

water absorbed by the amorphous part of the materials and the susceptibility of the substances to mixing with magnesium stearate becomes significantly larger.

\section{TABLE 2}

Tablet strength of spray dried lactose containing about $15 \%$ amorphous lactose, produced in a large spray dryer (L) (DCLactose 11) and a research spray dryer (I), respectively, using the same starting material

\begin{tabular}{lcc}
\hline Sample & $\begin{array}{c}\text { Compaction } \\
\text { pressure (MPa) }\end{array}$ & $\begin{array}{c}\text { Crushing } \\
\text { strength }(\mathrm{kg})\end{array}$ \\
\hline L & 75 & $8.2 \pm 0.3$ \\
$\mathrm{~L}$ & 150 & $14.8 \pm 0.3$ \\
L, lubricated & 150 & $8.3 \pm 0.2$ \\
1 & 75 & $7.4 \pm 0.4$ \\
1 & 150 & $13.7 \pm 0.5$ \\
1, lubricated & 150 & $6.3 \pm 0.2$ \\
\hline
\end{tabular}

Lubrication by $30 \mathrm{~min}$ mixing with $0.5 \%$ magnesium stearate in a Turbula mixer at $90 \mathrm{rpm}$. (Crushing strength \pm S.D.)
Fig. 4 illustrates that the thickness of the tablets is determined by the primary particles even at amorphous lactose grades up to $50 \%$. Comparing Fig. 4 to Figs. 2 and 3, apparently both consolidation and compactibility are a function of the primary particle size rather more than a function of the absolute quantity of amorphous lactose present in the product. Furthermore it is clear that the amorphous lactose does not act as a sort of lubricant which facilitates densification.

In order to get a better understanding of the mechanisms responsible for the observed increase in compactibility of the sieve fractions after spray drying, first the properties of the starting materials will be examined. Subsequently the role of the amorphous component in this matter will be discussed.

In Fig. 5 the crushing strength of compacts of the $\alpha$-lactose monohydrate sieve fractions is depicted in relation to the initial particle surface 

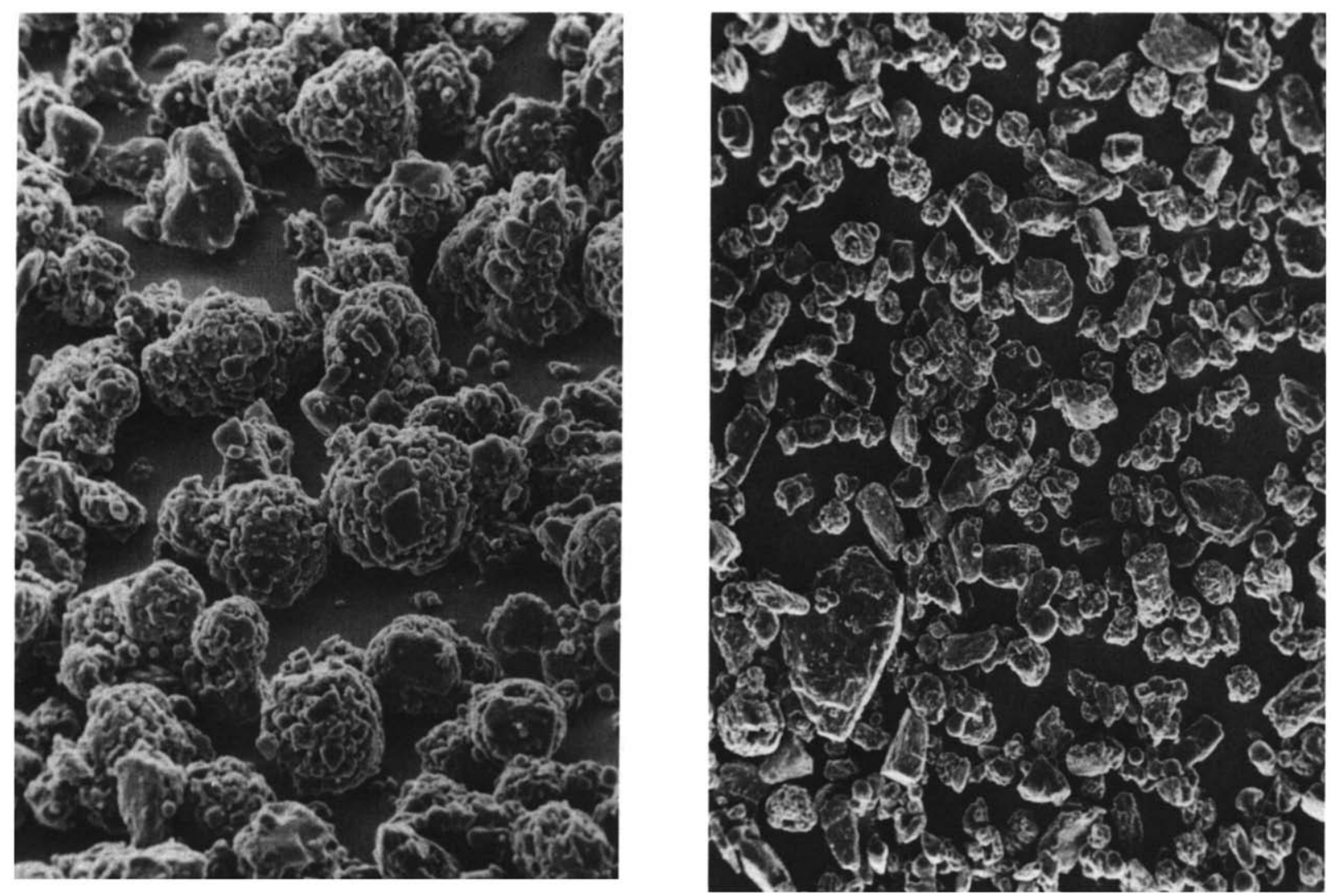

Fig. 1. Scanning electron micrographs of spray dried lactose samples containing $15 \%$ amorphous lactose (magnification $100 \times$ ). The products were manufactured with a large (DCLactose 11) and a small spray dryer, respectively, using the same starting material.

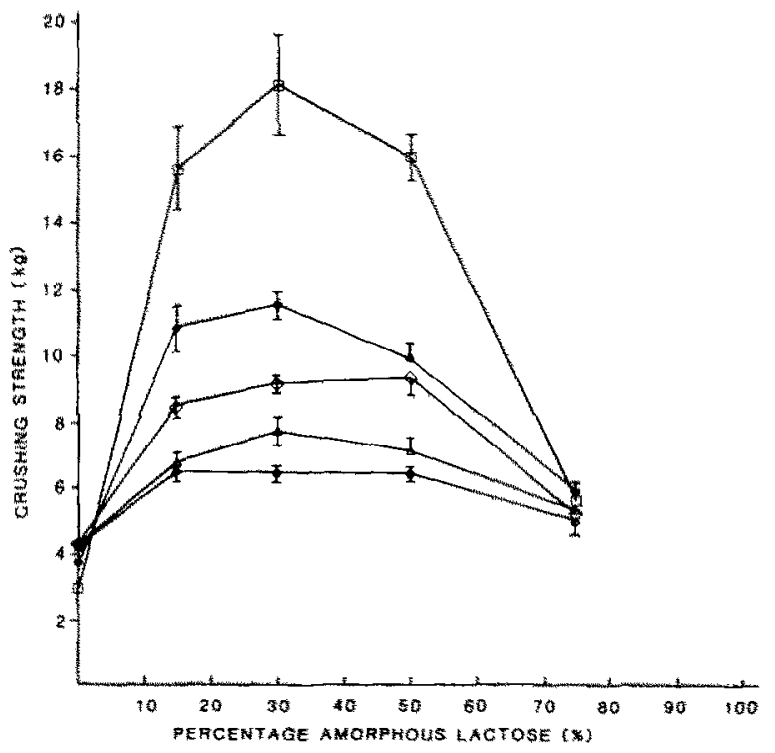

area $\left(S_{v}\right)$. As can be seen, a decrease in the initial particle size of the starting material does not give stronger tablets at the compaction load used. This seems to be somewhat suprising since it has been reported in two earlier studies (Vromans et al., 1985a; De Boer et al., 1986) that from smaller particles of $\alpha$-lactose monohydrate stronger tablets could be obtained. In these studies larger particles were used, however, whereas the compaction pres* sure was in general higher. It was indicated that at higher loads the differences in tablet strength were more pronounced. It was shown (De Boer et al.,

$\leftarrow$

Fig. 2. Crushing strength of tablets of spray dried lactose sampies, compressed at a compaction pressure of $75 \mathrm{MPa}$. The water content of the amophous lactose is about 2 otarting materials: $D, 1-8 \mu \mathrm{m} ;, 8-16 \mu \mathrm{m}_{*}=0,16-24 \mu \mathrm{m} ; \Delta, 24-32$ $\mu \mathrm{m}$ and $\mathrm{O}, 32-45 \mu \mathrm{m}$. 


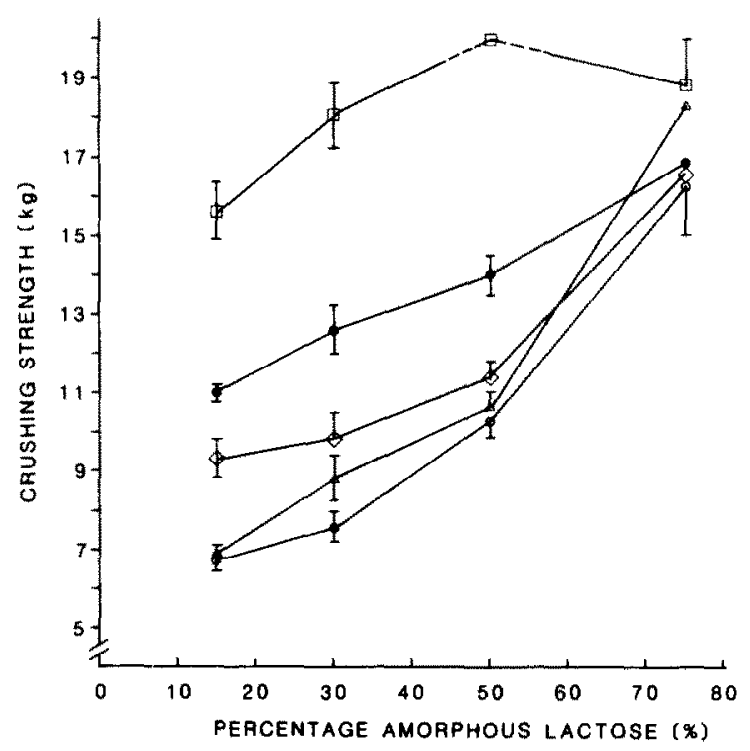

Fig. 3. Crushing strength of tablets of spray dried lactose samples, compressed at a compaction pressure of $75 \mathrm{MPa}$. The water content of the amorphous lactose is about $6 \%$. Symbols as in Fig. 2.

1986) that for the particle size fractions used fragmentation was the predominant mechanism of consolidation. However, the extent to which brit-

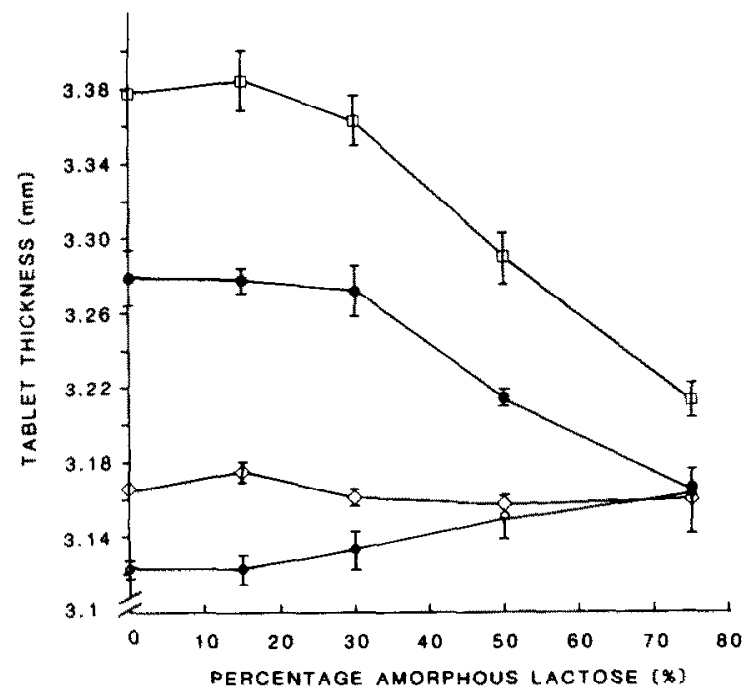

Fig. 4. Tablet thickness of spray dried lactose samples, compressed at a compaction pressure of $75 \mathrm{MPa}$. The water content of the amorphous lactose is about $2 \%$. Starting materials: $\square, 1-8 \mu \mathrm{m} ; \bullet, 8-16 \mu \mathrm{m} ; \vartheta, 16-24 \mu \mathrm{m}$; and $O, 32-45$ $\mu \mathrm{m}$.

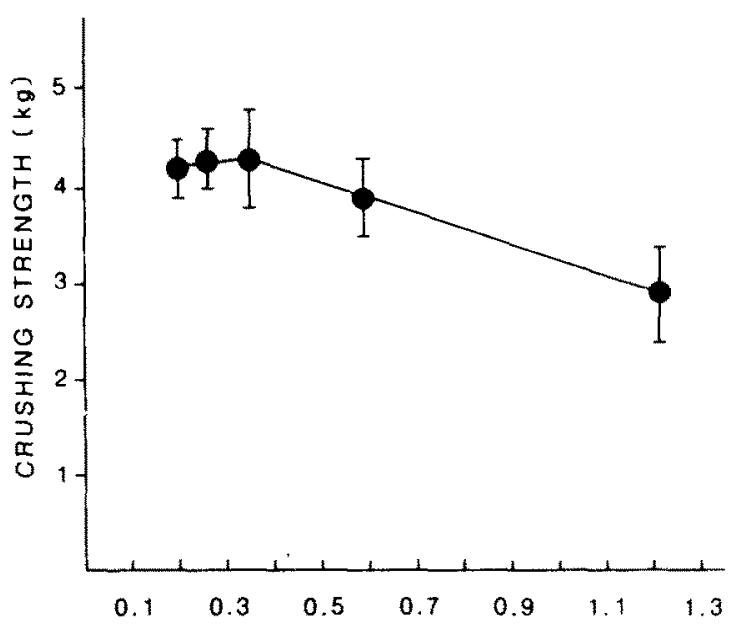

INITIAL SPECIFIC SURFACE AREA SV $\left(\times 10^{6} \mathrm{~m}^{-1}\right)$

Fig. 5. Crushing strength of tablets compressed from $\alpha$-lactose monohydrate sieve fractions at a pressure of $75 \mathrm{MPa}$, as a function of the initial specific surface area (Sv).

tle fracture occurred was dissimilar for the different sieve fractions. Large particles exhibited a larger degree of fragmentation than small particles. Initial differences in particle surface area were not levelled out, so that for smaller particles larger surface areas were available for bonding, providing for stronger tablets. In fact the theory of Orowan (1949) can be applied here, which states that when the size of crystals decreases, there is an increase in stress necessary to cause extension of any crystal cracks. Fig. 6 illustrates the ratio between the porc surface area of tablets compressed at $75 \mathrm{MPa}$, calculated from mercury porosimetry measurements, and the initial particle surface area $\left(S_{c}\right)$, as a function of initial powder surface area $\left(S_{c}\right)$. This ratio, which represents in fact a surface area multiplication, can be considered to be an indication of the degree of fragmentation (Alderborn and Nyström, 1985). From Fig. 6 it can be seen that small particles fragment only slightly. For this reason it is obvious that densification of the small particle size fractions must occur to a large extent by particle rearrangement and by plastic and elastic deformation, respectively. Because of the large number of contact points within the powder bed an important amount of friction must exist. The data as shown in Fig. 5 point out that this apparently does not result in 


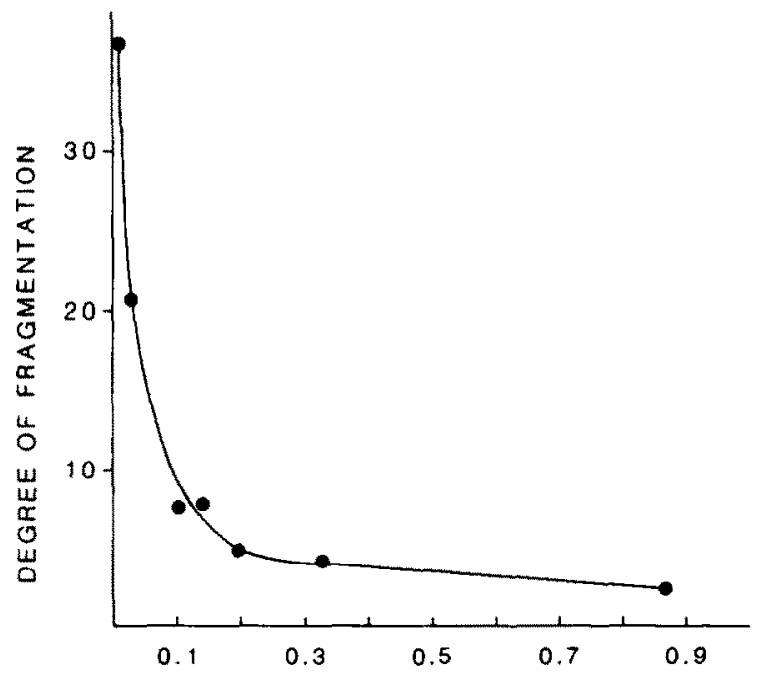

INITIAL POWDER SURFACE AREA $S c\left(m^{2} / g\right)$

Fig. 6. Ratio between tablet pore surface area of tablets compressed at $75 \mathrm{MPa}$ and the initial powder surface area $(\mathrm{Sc})$, respectively, to be considered as a degree of fragmentation, as a function of the powder surface area (Sc) of the $\alpha$-lactose monohydrate sieve fractions.

strong bonding, however. Also it is to be noticed that, if there is an increasing contribution of plastic deformation at decreasing particle size, this seems not to contribute to strong bonding either. Hence it may be expected that elastic relaxation has an important effect on the crushing strength. Thus it is clear that with decreasing particle size another mechanism of consolidation will become dominant. As a result of this it can be argued that the unique proportionality between tablet pore surface area and binding surface area, existing for larger particles of $\alpha$-lactose monohydrate (De Boer et al., 1986), cannot be valid in this respect, i.e. it must have changed. This can be seen in Fig. 7. It can be observed that with decreasing particle size the deviation from the straight line increases, and this is actually what was to be expected from Fig. 6 and the foregoing discussion. The prerequisite to get a linear relationship between tablet strength and tablet pore surface area is obviously that fragmentation is the predominant mechanism of consolidation, or, in other words, fragmentation is necessary to enable potential bonding surfaces to come into close contact. This is confirmed by the

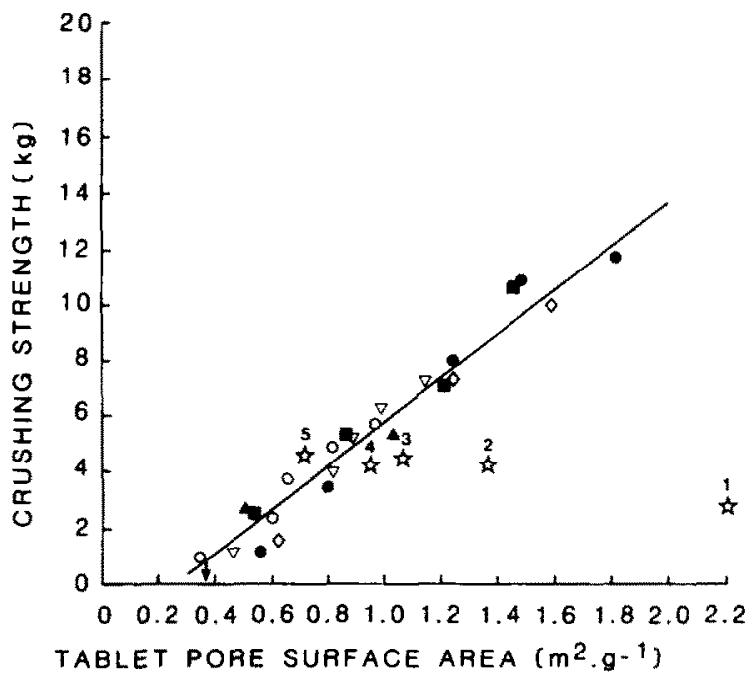

Fig. 7. Crushing strength of tablets compressed from different crystalline lactoses at various compaction pressures, as a function of the tablet pore surface area, calculated from mercury porosimetry measurements. - anhydrous $\alpha$-lactose $100-125$ $\mu \mathrm{m} ; \boldsymbol{\Lambda}$, crystalline $\beta$-lactose $100-125 \mu \mathrm{m} ; \mathbf{v}$, roller dried $\beta$ lactose $100-125 \mu \mathrm{m} ; \alpha$-lactose monohydrate $32-45 \mu \mathrm{m}, \varnothing$; 125-160 $\mu \mathrm{m}, \nabla$; and $315-400 \mu \mathrm{m}, O$, respectively. Data abstracted from part 2 and 3 of this series (Vromans at al., 1985; De Boer et al., 1986). The values of the $\alpha$-lactose monohydrate samples which are indicated with figures, are obtained from tablets compressed at $75 \mathrm{MPa}$. $1-8 \mu \mathrm{m} ;{ }^{2}$, $8-16 \mu \mathrm{m}$; ${ }^{3}, 16-24 \mu \mathrm{m} ; \sim^{4}, 24-32 \mu \mathrm{m}$; and $\tau^{5}, 32-45 \mu \mathrm{m}$.

observation that the densification of small particles is poor compared with that of large particles (Fig. 4 and Vromans et al., 1985a).

A totally different approach to explain the deviation from the straight line is to assume that there exists a difference in bonding efficacy between the original outer surface of the particles and the fresh surface created by fragmentation. This might be caused by e.g. adsorptive moisture (Vromans et al., 1986). This will be brought out only when there is a small degree of fragmentation in which case the initial outer surface area has an important contribution to the total binding surface area (Fig, 6).

When the sieve fractions of $\alpha$-lactose monohydrate are covered by a layer of amorphous lactose, a significant increase in tablet strength is observed with decreasing particle size (Fig. 8). It is likely to 


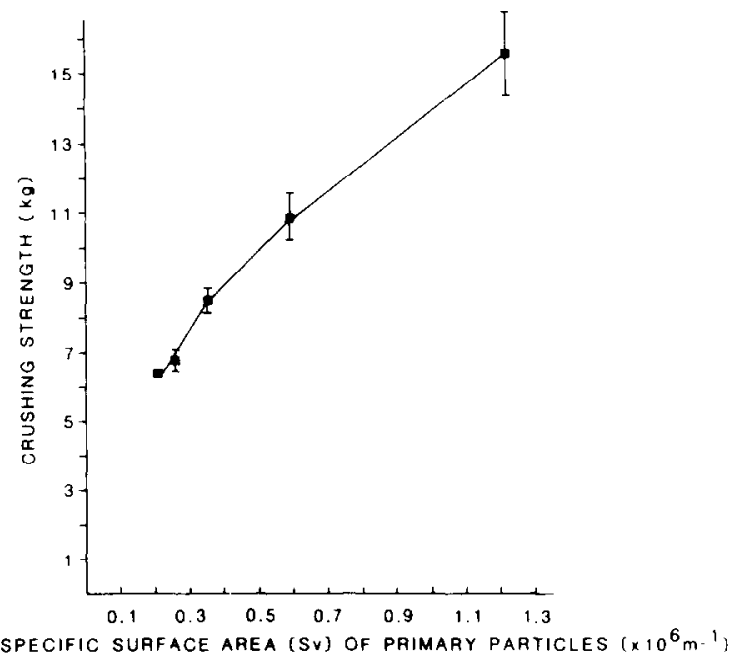

Fig. 8. Crushing strength of tablets compressed from spray dried lactose samples containing $15 \%$ amorphous lactose, compressed at a compaction pressure of $75 \mathrm{MPa}$, as a function of the specific surface area (Sv) of the primary particles. The water content of the amorphous lactose is about $2 \%$.

assume that the glass on the outer surface of the particles provide for stronger bonds and that possibly in addition a part of the elastic recovery has been overcome by this. As it has already been suggested (Vromans et al., 1986), the good binding properties of spray dried lactose might be considered to be mainly caused by the good binding of the amorphous lactose layer which covers the $\alpha$-lactose monohydrate particles. Only $15 \%$ of glass is already sufficient to increase compactability considerably (Fig. 2). Also it is noticed that higher percentages do not further increase crushing strength dramatically until the amorphous part of the substance gets a dominating role in consolidation (Figs. 2-4). It is of interest to know what the effect is of smaller amounts of amorphous lactose. However, a spray dried lactose product which contains only a few percent of amorphous material cannot be manufactured, since the solubilized quantity in the aqueous suspension at the moment of spray drying determines the amount of the amorphous component in the final product. It appeared not to be possible to get lower percentages of glass than about 10-15\% (see Materials and Methods). For this reason we have suspended dicalcium phosphate dihydrate (DCP, $\overline{\mathrm{d}}=10 \mu \mathrm{m}$ ) in solutions of lactose. Fig. 9 illustrates the increase in crushing strength of DCP as a result of the surface covering with amorphous lactose. $\mathrm{Ob}$ viously there is only a small quantity of glass necessary for an important increase in compactibility. The surface layer apparently has a great contribution to the tablet strength. Yet this is somewhat surprising since DCP is known to fragment intensively under load. It is e.g. not susceptible to magnesium stearate mixing (De Boer et al., 1978). The lubricant film can be compared here with the amorphous lactose layer, although the amount of amorphous lactose is larger than the quantity of magnesium stearate.

When the same DCP is mixed with spray dried amorphous lactose (Fig. 9) a better understanding of the mechanism of bonding enhancement can be obtained. Mixing of the two substances will most probably result in random mixtures, whereas spray drying results in a sort of ordered mixture in which the binder is situated at the bonding site. The curve of the crushing strength reflects in fact the saturation of the surface of the particles. This conclusion supports the results of Seager et al. (1982) who found that variation in binder distribution leads to considerable differences in the tableting properties of a product. The amount of

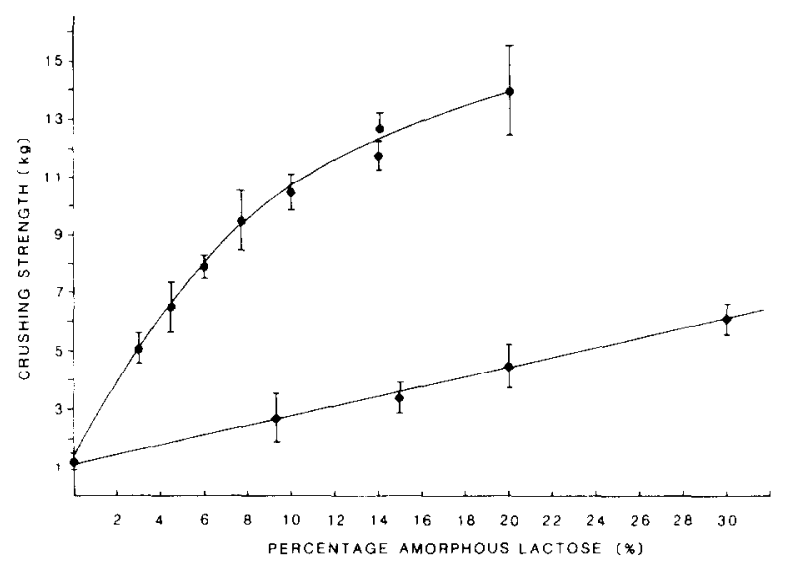

Fig. 9. Crushing strength of tablets of DCP, spray dried from lactose solutions (๑), and of mixtures of DCP and spray dried fully amorphous lactose, respectively $(\uparrow)$, compressed at a compaction pressure of $75 \mathrm{MPa}$. The water content of the amorphous lactose is about $2 \%$. 
binder present at the surface of the particle, i.e. at the bonding site, is the most important factor influencing compactibility. The tablet strength increases until the particle surface area is totally covered with the binder. Higher binder percentages do not further increase compactibility. Consequently this means that the primary particles must be considered to act as a sort of carriers, which are responsible for the size of the ultimate contact surface area.

In their studies on direct compression of tablets, Nyström et al. (1982) and Nyström and Glazer (1985) concluded that the efficacy of a dry binder, which is ordered on the particle surface of a certain compound, is highly dependent on the fragmentation propensity of the particular substance. The technique to cover a material with a fine binder resulted in stronger tablets for the compounds, which were less prone to fragment during compaction.

Mercury porosimetry measurements showed that the pore surface areas of the compacted spray dried products with 15\% amorphous lactose had about the same values as those of tablets compressed from the starting material at the same load. This means that particle fragmentation is not hindered by the amorphous lactose. As a matter of fact we have two opposite effects determining compactibility; firstly, it is recognized that small particles have a large surface area covered with amorphous lactose, while these particles fragment only slightly (Fig. 6). This can be looked upon as a large bonding potential. Secondly, consolidation of small particles is poor, as it has been concluded from the Figs. 4 and 5. Obviously the first factor dominates the binding properties of the products. Nevertheless it is important to realize that possibly much higher compactibility values would be obtained if consolidation was somewhat better.

In conclusion, it is demonstrated that amorphous lactose acts as a binder. Its efficacy is determined by both the size and the consolidation of the particles on which it is situated.

\section{References}

Alderborn, G. and Nyström, C., Studies on direct compression of tablets, Part 14, The effect of powder fineness on the relation between tablet permeametry surface area and compaction pressure. Powder Technol., 44 (1985) 37-47.

De Boer, A.H., Bolhuis, G.K. and Lerk, C.F., Bonding characteristics by scanning electron microscopy of powders mixed with magnesium stearate. Powder Technol., 20 (1978) $75-82$.

De Boer, A.H., Vromans, H., Lerk, C.F., Bolhuis, G.K., Kussendrager, K.D. and Bosch, H., Studies on tableting propcrtics of lactose, Part 3, The consolidation bchaviour of sieve fractions of crystalline $\alpha$-lactose monohydrate. Pharm Weekbl. Sci. Ed., 8 (1986) 145-150.

Bolhuis, G.K., Reichman, G., Lerk, C.F., Van Kamp, H.V. and Zuurman, K., Evaluation of anhydrous $\alpha$-lactose, a new excipient in direct compression. Drug Develop. Ind. Pharm., 8 (1985) 1657-1681.

Fell, J.T. and Newton, J.M., The productions and properties of spray dried lactose, Part 3, The compaction properties of samples of spray dried lactose produced on an experimental dryer. Pharm. Acta Helv., 46 (1971) 441-447.

Kussendrager, K.D., de Hoog, P. and van Leverink, J., Some physical properties of spray dried lactose with respect to stability and compression. Acta Pharm. Suec., 18 (1981) 94-95.

Nyström, C., Mazur, J. and Sjögren, J., Studies on direct compression of tablets, part 2; the influence of the particle size of a dry binder on the mechanical strength of tablets. Int. J. Pharm., 10 (1982) 209-218.

Nyström, C. and Glazer, M., Studies on direct compression of tablets, part 13; the effect of some dry binders on the tablet strength of compounds with different fragmentation propensity. Int. J. Pharm., 23 (1985) 255-263.

Orowan, E., Fracture and strength of solids. Rep. Progr. Phys., 12 (1949) 185-232.

Seager, H., Relationship between the process of manufacture and the structure and properties of granules and tablets. Proceedings Pharm. Tech. Conference 1982, New York City, Pharmaceutical Technology Publications, Springfield, OR., U.S.A., p. 175-210.

Vromans, H., De Boer, A.H., Bolhuis, G.K., Lerk, C.F. and Kussendrager, K.D., Studies on tableting properties of lactose, Part 1, The effect of initial particle size on binding properties and dehydration characteristics of lactose. Acta Pharm. Suec, 22 (1985a) 163-172.

Vromans, H., De Boer, A.H., Bolhuis, G.K., Lerk, C.F., Kussendrager, K.D. and Bosch, H., Studies on tableting properties of lactose, Part 2, Consolidation and compaction of different types of crystalline lactose. Pharm. Weekbl. Sci. $E d, 7$ (1985b) 186-193.

Vromans, H., Bolhuis, G.K., Lerk, C.F., Kussendrager, K.D. and Bosch, H., Studies on tableting properties of lactose, Part 6, Consolidation and compaction of spray dried amorphous lactose. Acta Pharm. Suec., 23 (1986) 231-240. 